\title{
Gold Plating in Submarine Telephone Cable Repeaters
}

\author{
RELIABLE CAPACITORS FOR EXTENDED SERVICE
}

\section{S. Girling}

I.T.T. Components Group Europe, Paignton, Devon

Thousands of miles of submarine telephone cables form an important and growing part of the world pattern of communications. Repeaters every few miles along these cables maintain signal strengths, and many of the components in these repeaters are gold plated to ensure freedom from deterioration or failure in service.

Growth of the world telecommunications network continues to surge forward on three main frontstelephones, television and, most recently, transmission of data. To meet the demand for more international links development has continued in two principal directions. These are communications satellites and submarine cables. The former have taken much of the spotlight in recent years and are very suitable for international television transmissions. However, for telephone conversations the synchronous communications satellite has the drawback that, because of its distance 22,300 miles above the Earth's surface, there is a perceptible time-lag as the signal travelling at the speed of light, 186,000 miles per second, goes up from the transmitter to the satellite and down again to the receiver. The total distance travelled by the signal is thus about 44,600 miles and this takes a quarter of a second. In a two-way telephone conversation there will be a

Fig. 1 A submarine cable repeater under construction by Standard Telephone and Cables showing the large number of gold plated components. Each repeater contains up to six high voltage and 30 low voltage gold-plated capacitors quarter of a second after one speaker ceases talking before his hearer starts to reply and a further quartersecond interval before the first speaker receives the start of the reply, i.e. there is a half-second gap in the conversation every time one speaker gives way to the other. This has proved a major obstacle to satellite telephone circuits.

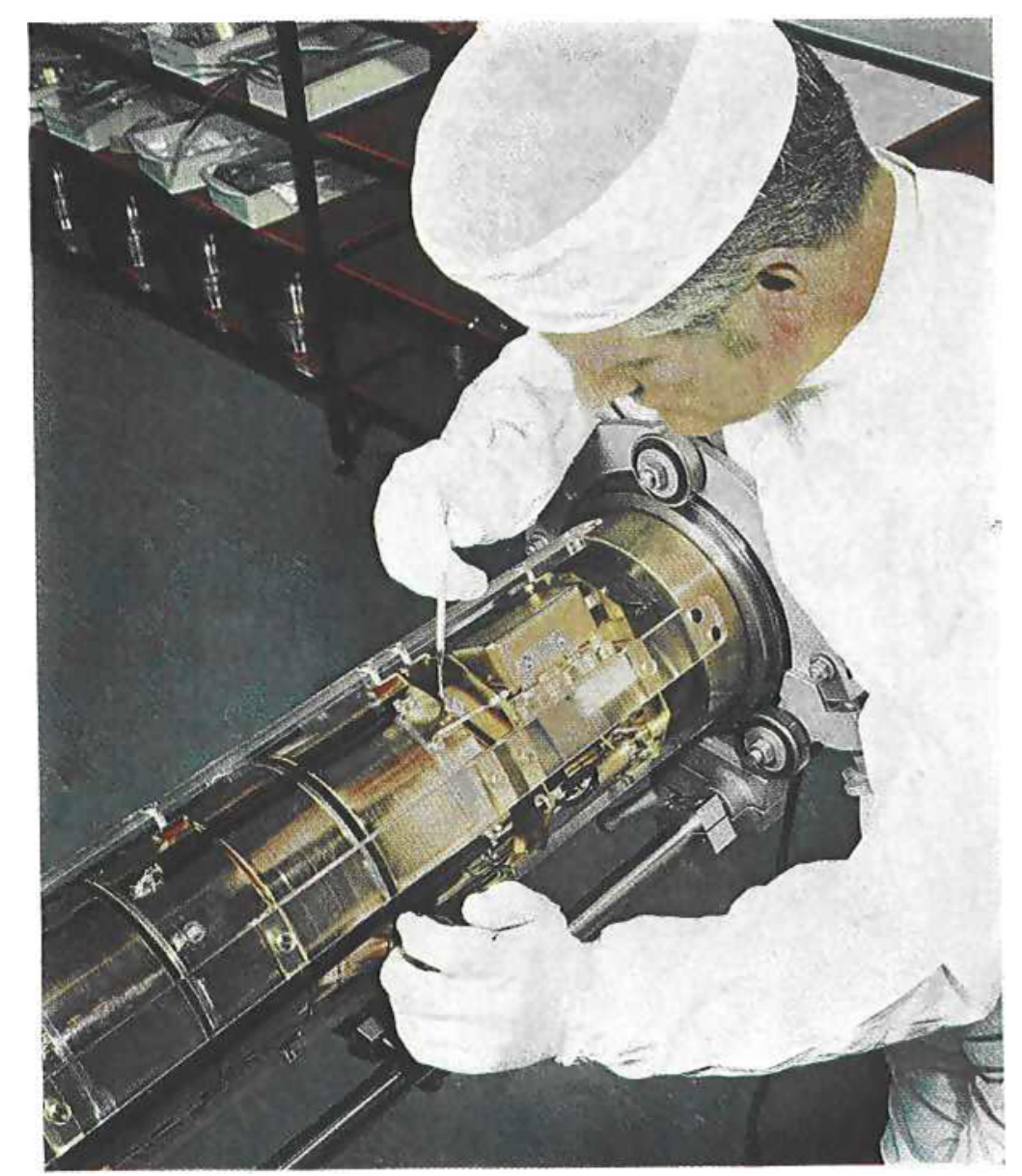


By contrast, a telephone conversation via a submarine cable involves only a few thousand miles travel by the signal and delays are negligible. Cables have been developed for telephony over the last twenty years from the original capacity of a few tens of circuits to the point today where nearly 2,000 simultaneous conversations can take place over those most recently laid.

A very large proportion of these submarine cables have been designed and produced by the Submarine Systems Group of Standard Telephones \& Cables Limited, an associate of I.T.T. Such cables include the transatlantic series known as TAT-1, TAT-2, CANTAT, and many others, and the Commonwealth Pacific COMPAC cable, and that connecting Europe with South Africa.

It is clear that damage to or failure of such a cable will be an expensive business. The difficulty of recovering a deep-sea cable is obvious. Futhermore, there will probably be a communications gap of ten days or so while a cable ship recovers and repairs the cable. Thus it is estimated that the direct costs of a cable failure may be $£ 250,000$, to which must be added the loss of revenue while the cable is out of action. It is a striking tribute to the design and construction of these cables that so far the only failures have been caused by physical damage to the cables, for example by trawling, and none by any inherent defect.

The British Post Office, which operates the cables, requires a twenty-five year guarantee of defectfree operation by the submarine cables, and hence by all their components. Design by Standard Telephones \& Cables is to British Post Office specifications and originally used the philosophy of proven integrity, which meant that only well established and proven designs were used.

Repeaters are installed every few miles along the cable to compensate for attenuation of signal. These repeaters are in effect two amplifiers back to back so that signals in each direction are amplified. This is accomplished by using the lower frequencies in one direction and the higher frequencies in the other. One amplifier is fed through low pass filters and the other through high pass filters. The power to operate the repeaters is supplied from the ends of the cable; thus the first filters in the repeater are the power separating filters, which separate the signal from the power. The capacitors in these filters have to stand the full voltage of the system and are probably the most highly stressed components in the repeater. Such repeaters must be sturdy and reliable. Earlier models used valves but the latest are transistorised. These now operate at a bandwidth of from $300 \mathrm{kHz}$ to $14 \mathrm{MHz}$. Increasing bandwidth has led to repeaters being spaced more closely together but it has permitted substantial increases in the number of telephone channels.

Figure 1 shows the internal construction of a repeater, from which it can be seen at once that many of its components are gold plated. The properties of gold are especially valuable in electrical apparatus which must operate for years without fault and without inspection. In this instance the gold plating prevents any corrosion of the components and, of course, has the additional advantage of good solderability. Gold has the great advantage that, as far as is known, it does not grow metal whiskers. These are crystalline growths which could easily short circuit the repeater during its lifetime. Such growths

Fig. 2 A group of high voltage paper capacitors in carrying cradles ready for dispatch from the Paignton works of I.T.T. Components Group Europe. The can of each capacitor is gold plated inside and out to prevent metal whisker growth

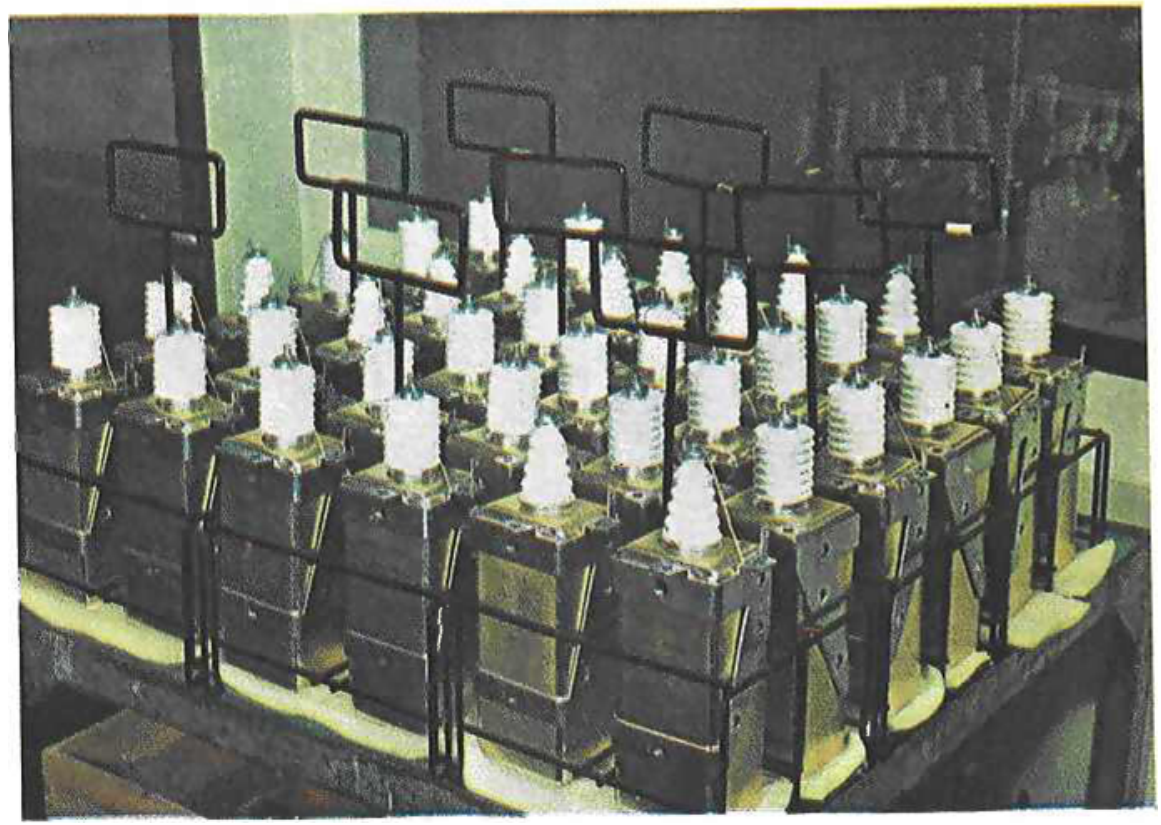


Fig. 3 The parts of a high voltage paper capacitor used in repeaters manufactured by Standard Telephones \& Cables. They include four elements comprising moisture-free paper with aluminium foil electrodes (below centre), paper liners and packing pieces, a small bellows (below right), and the gold-plated copper cans (above right)

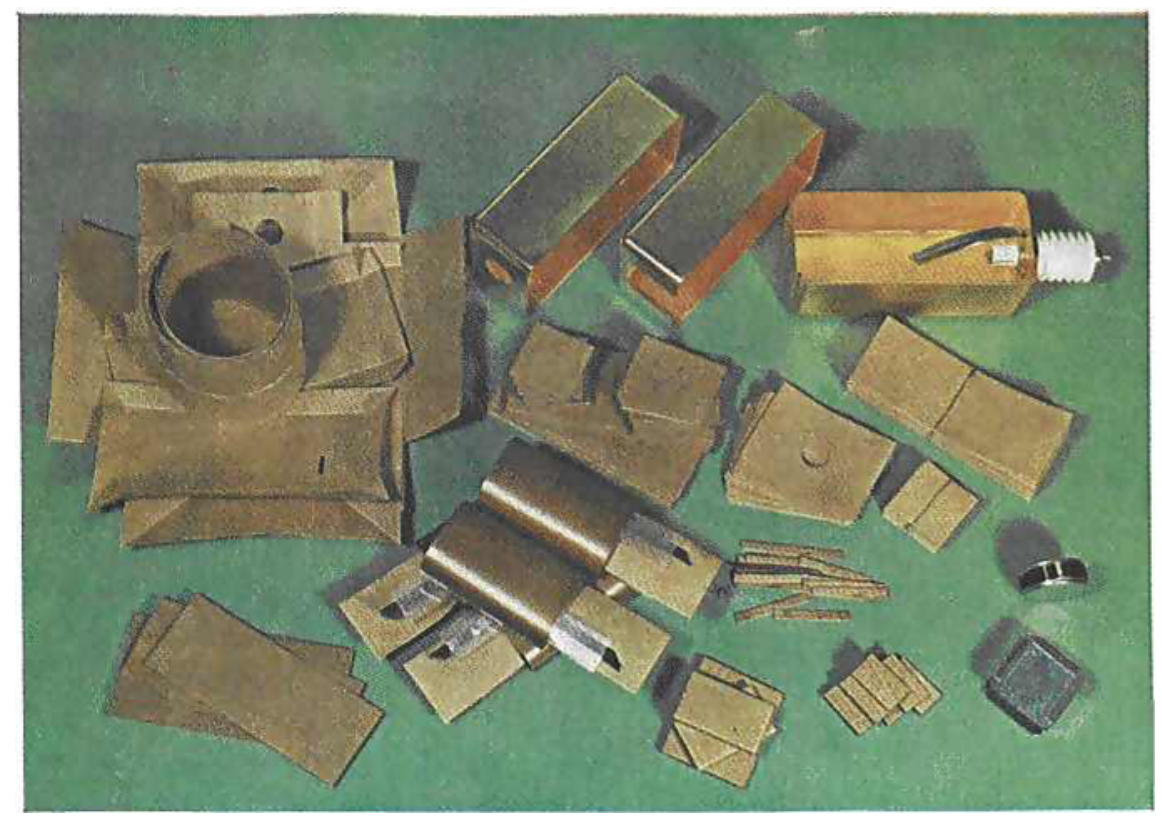

are particularly a problem with normal finishes such as tin.

Each repeater contains a large number of capacitors. These are of three main types and are manufactured by the Capacitor Division of I.T.T. Components Group Europe at Paignton. There are four or six high voltage paper capacitors per repeater for the power separating filters. In addition there are 20 to 30 low voltage paper capacitors in the amplifier circuits. The third group is mica capacitors.

A group of high voltage capacitors is shown in Fig. 2 and the parts of one are shown in Fig. 3. It can be seen that the casing of each $(2.5$ in $\times 2$ in $\times$ $5 \frac{13}{16}$ in) is gold plated inside and out and the same applies to the low voltage capacitors.

The cable operates at about 9 kilovolts d.c. and each high voltage paper capacitor contains four $3 \mathrm{kV}$ elements to give a nominal $12 \mathrm{kV}$ capability. Each element consists of impregnated paper with aluminium foil electrodes. The paper is vacuumdried to remove moisture and is impregnated with degasified mineral oil under pressure. Bubbles must be eliminated to prevent ionisation and for this reason the assembly includes a bellows. Liners and packing pieces of paper are impregnated also. The copper can is gold plated to a thickness of 20 to 50 microinch. Capacitor elements and packers are put into the can which is then vacuum filled with the impregnating oil at $100^{\circ} \mathrm{C}$. The unit is then cooled to $-40^{\circ} \mathrm{C}$, permitting extra oil to enter and to fill the can completely, and the can is then sealed at that temperature. On recovery to normal temperature the bellows becomes compressed and maintains the pressure inside the can. Sealing of the gold plated can is carried out using 60/40 lead-tin solder, with which the gold possesses good solderability.

The low voltage paper capacitors are of a more conventional tubular design. They employ the same dielectrics but, of course, of reduced thickness commensurate with the working voltage. Once again the cases are gold-plated.

The mica capacitors are resin moulded, fully bonded, packed mica plates with silvered electrodes. The terminal wires are gold plated for the same reason as before.

Very strict quality control is maintained at all stages of capacitor manufacture, which is carried out in a 'clean' area of the factory. Post Office inspectors are present both at Paignton and at Woolwich, where the repeaters are assembled. Visual checks result in rejection for the slightest scratch in the gold plating, since a scratch might cause degradation leading to failure. Each completed high voltage paper capacitor undergoes a total of ten weeks testing, consisting of two weeks of electrical and physical tests followed by six weeks of ageing and a further two weeks of repeated electrical and physical tests.

The success of the testing programme is clear. Performance records show that not one submarine repeater capacitor has failed in operating service since such capacitors were first used in submarine cables in 1960.

The increasing volume of traffic over these submarine telephone cables renders it certain that demand for efficient repeaters will continue to be high. The inertness of gold plating of repeater components will make its contribution to failure-free operation. 